\title{
Impact of Lean on patient cycle and waiting times at a rural district hospital in KwaZulu-Natal
}

\begin{tabular}{|c|c|}
\hline \multicolumn{2}{|c|}{$\begin{array}{l}\text { Authors: } \\
\text { Logandran Naidoo }^{1} \\
\text { Ozayr H. Mahomed }\end{array}$} \\
\hline \multicolumn{2}{|c|}{$\begin{array}{l}\text { Affiliations: } \\
{ }^{1} \text { KwaZulu-Natal Department } \\
\text { of Health, Grey's Hospital, } \\
\text { South Africa }\end{array}$} \\
\hline \multicolumn{2}{|c|}{$\begin{array}{l}{ }^{2} \text { Discipline of Public Health } \\
\text { Medicine, University of } \\
\text { KwaZulu-Natal, South Africa }\end{array}$} \\
\hline \multicolumn{2}{|c|}{$\begin{array}{l}\text { Research Project no.: } \\
\text { BE097/11 }\end{array}$} \\
\hline \multicolumn{2}{|c|}{$\begin{array}{l}\text { Corresponding author: } \\
\text { Ozayr Mahomed, } \\
\text { mahomedo@ukzn.ac.za }\end{array}$} \\
\hline \multicolumn{2}{|c|}{$\begin{array}{l}\text { Dates: } \\
\text { Received: } 06 \text { Nov. } 2015 \\
\text { Accepted: } 03 \text { Mar. } 2016 \\
\text { Published: } 26 \text { July } 2016\end{array}$} \\
\hline \multicolumn{2}{|c|}{$\begin{array}{l}\text { How to cite this article: } \\
\text { Naidoo L, Mahomed OH. } \\
\text { Impact of Lean on patient } \\
\text { cycle and waiting times at a } \\
\text { rural district hospital in } \\
\text { KwaZulu-Natal. Afr J Prm } \\
\text { Health Care Fam Med. } \\
\text { 2016;8(1), a1084. http:// } \\
\text { dx.doi.org/10.4102/phcfm. } \\
\text { v8i1.1084 }\end{array}$} \\
\hline \multicolumn{2}{|c|}{$\begin{array}{l}\text { Copyright: } \\
\text { (C) 2016. The Authors } \\
\text { Licensee: AOSIS. This } \\
\text { is licensed under the } \\
\text { Creative Commons } \\
\text { Attribution License. }\end{array}$} \\
\hline \multicolumn{2}{|l|}{ Read online: } \\
\hline 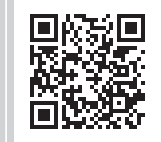 & $\begin{array}{l}\text { Scan this QR } \\
\text { code with your } \\
\text { smart phone or } \\
\text { mobile device } \\
\text { to read online. }\end{array}$ \\
\hline
\end{tabular}

Background: Prolonged waiting time is a source of patient dissatisfaction with health care and is negatively associated with patient satisfaction. Prolonged waiting times in many district hospitals result in many dissatisfied patients, overworked and frustrated staff, and poor quality of care because of the perceived increased workload.

Aim: The aim of the study was to determine the impact of Lean principles techniques, and tools on the operational efficiency in the outpatient department (OPD) of a rural district hospital.

Setting: The study was conducted at the Catherine Booth Hospital $(\mathrm{CBH})$ - a rural district hospital in KwaZulu-Natal, South Africa.

Methods: This was an action research study with pre-, intermediate-, and post-implementation assessments. Cycle and waiting times were measured by direct observation on two occasions before, approximately two-weekly during, and on two occasions after Lean implementation. A standardised data collection tool was completed by the researcher at each of the six key service nodes in the OPD to capture the waiting times and cycle times.

Results: All six service nodes showed a reduction in cycle times and waiting times between the baseline assessment and post-Lean implementation measurement. Significant reduction was achieved in cycle times $(27 \% ; p<0.05)$ and waiting times (from 11.93 to $10 \mathrm{~min} ; p=0.03$ ) at the Investigations node. Although the target reduction was not achieved for the Consulting Room node, there was a significant reduction in waiting times from 80.95 to $74.43 \mathrm{~min},(p<0.001)$. The average efficiency increased from $16.35 \%$ (baseline) to $20.13 \%$ (post-intervention).

Conclusion: The application of Lean principles, tools and techniques provides hospital managers with an evidence-based management approach to resolving problems and improving quality indicators.

\section{Introduction}

The White Paper for the Transformation of the Health System in South Africa ${ }^{1}$ set the strategic direction of the district health system (DHS) as the vehicle for primary health care (PHC) services in the democratic South Africa. The district hospital plays an integral role in the DHS by serving as the first point of referral for the PHC clinics; providing supervision, training, and outreach services to the referring facilities; ${ }^{2}$ and acting as a gatekeeper to the higher level of services. ${ }^{2}$

There are numerous challenges that are inherent in the health system that affect district hospitals. Key amongst these challenges that affect the district hospitals are: the quadruple burden of disease, ${ }^{3}$ new and emerging epidemics such as multidrug-resistant (MDR) and extensively drug-resistant (XDR) tuberculosis, poor quality of care, operational inefficiencies, inadequate and inappropriately trained healthcare personnel, inequitable distribution of healthcare personnel, inefficient and inequitable resource allocation (financial and equipment), and deficiencies in managerial capacity and leadership. ${ }^{4}$

The National Service Delivery Agreement (NSDA) has proposed strengthening patient care and satisfaction, accreditation of health facilities for compliance, and improved health infrastructure availability, amongst others, as key to strengthening health systems' effectiveness. ${ }^{5}$ In order to strengthen patient care and satisfaction and provide patient-centred care, the National Department of Health $(\mathrm{NDoH})$ identified the six most critical areas for patient-centred care $^{6}$ based on the Constitution of South Africa, the Batho Pele principles, the Patients' Rights Charter, and the National Core Standards (NCS). ${ }^{7}$ The six priority areas focus on three domains namely, Patients' Rights, Patient Safety, Clinical Governance and Care, and Clinical Support Services. Reducing 
waiting times and queues (for administration, assessment, diagnosis, pharmacy, surgery, and referral and transfer time), have been identified as a key priority intervention within the Patients' Rights domain. Prolonged waiting time is a source of patient dissatisfaction with health care ${ }^{8}$ and is negatively associated with patient satisfaction. ${ }^{9}$ Prolonged waiting times in many district hospitals result in many dissatisfied patients, overworked and frustrated staff, and poor quality of care because of the perceived increased workload.

Lean thinking has been introduced as a quality improvement methodology at many hospitals worldwide ${ }^{10}$ to reduce waste or non-value-added elements from the processes so that patients are given greater value. ${ }^{11}$ Waste in a hospital setting is the time spent waiting between and for services. When waste is removed, patients flow smoothly and continuously and this can increase the efficiency, quality, and safety of patient care. $^{12}$

Lean thinking has been applied in the emergency departments (EDs) in many Western countries. ${ }^{13}$ In South Africa, Lean projects have been implemented in many facilities to improve patient flow between their casualty department and other wards, and a tertiary hospital in the Western Cape used Lean principles to reduce the waiting time at the outpatient pharmacy. ${ }^{14}$ A case study conducted using Lean thinking at the orthopaedic outpatient clinic at a secondary-level hospital resulted in a 31\% reduction in total time spent at the clinic and a 39\% reduction in patient waiting times. $^{15}$

There is a paucity of evidence that Lean (systems or thinking) principles have been used to address operational inefficiencies at district hospitals. We present the findings of our case study in which Lean thinking was applied at the outpatient department (OPD) of a rural district hospital. The aim of the study was to determine the impact of Lean thinking on patient waiting times at the OPD.

\section{Research methods and study design Study design and setting}

This was an action research study (Figure 1). The study was conducted at the Catherine Booth Hospital (CBH), a 170-bed rural district hospital situated in Amatikulu, in the uThungulu Health District on KwaZulu-Natal's North Coast. The hospital offers generalist medical and surgical services for both inpatients and outpatients, serving a population of over 200000 people. uThungulu Health District, as most rural areas in KwaZulu-Natal, mirrors the quadruple burden of disease afflicting South Africa, namely communicable diseases such as HIV and TB, maternal and child morbidity and mortality, non-communicable diseases, and accidental and non-accidental trauma and injuries.

At the time of the study, the OPD consisted of three consulting rooms, a nursing assessment station, a four-bed emergency cubicle, and a waiting area. The study includes all major areas (patient administration, screening, consultation rooms, investigations, X-ray department and/or pharmacy) through which a patient usually has to pass in the health care service delivery process before exiting the hospital.

\section{The process and application of Lean tools and techniques}

\section{Kaizen team meetings ${ }^{16,17}$ (quality improvement team meetings)}

After a pre-intervention briefing meeting, two action research cycles were completed and three kaizen team meetings were held. ${ }^{16,17}$ During each meeting, the facilitator delivered a slide presentation that included the latest results of the cycle- and waiting time measurements. The 5-why analysis ${ }^{17}$ and the A3 tool $^{18}$ were used for problem solving.

The pre-intervention briefing meeting sought to explain the process of Lean to kaizen team members, and was well understood even though it was a new concept to them. The tools and techniques that were used were simple enough for the kaizen team members to use themselves in the meetings. The researcher, however, developed the value stream maps (VSMs) with the results of the cycle and waiting time measurements. This graphical representation of the flow of patients through the OPD gave everyone a more vivid and clear description of the process (Figure 1).

Team members also found the 5-why technique and 5-S tool ${ }^{17}$ valuable in identifying wastes and creating an environment suitable for process enhancement. The targets that were set by the team were realistic. Owing to factors such as establishing patient rapport, counselling patients, standard history-taking and examination, which lengthen the time of the patient consultation, it was impossible to set a greater cycle time reduction target.

\section{The $\mathrm{A} 3$ reports}

Three A3 reports, each of which was developed at every kaizen team meeting, proved to be successful as tools with which to engage with kaizen team members in problem solving, using techniques such as 5-why. Non-value-adding items (muda), which contributed to long cycle and waiting times, were identified and listed in the A3 tool. An action plan with specific actions, responsible persons, and time frames, was compiled. This was implemented immediately after the kaizen team meeting, which then heralded the start of the next action research cycle.

\section{Value stream maps}

An average outpatient would go through the six service nodes in the sequence described above, each of which is generally preceded by waiting in a queue. It is perceived that a patient values receiving (quality) services at some or all of the service nodes in the OPD rather than waiting in queues (muda). The time spent within each of the service nodes (being 'processed') is reflected in the VSM as cycle times, interspersed with the non-value-adding waiting time before each service node. 


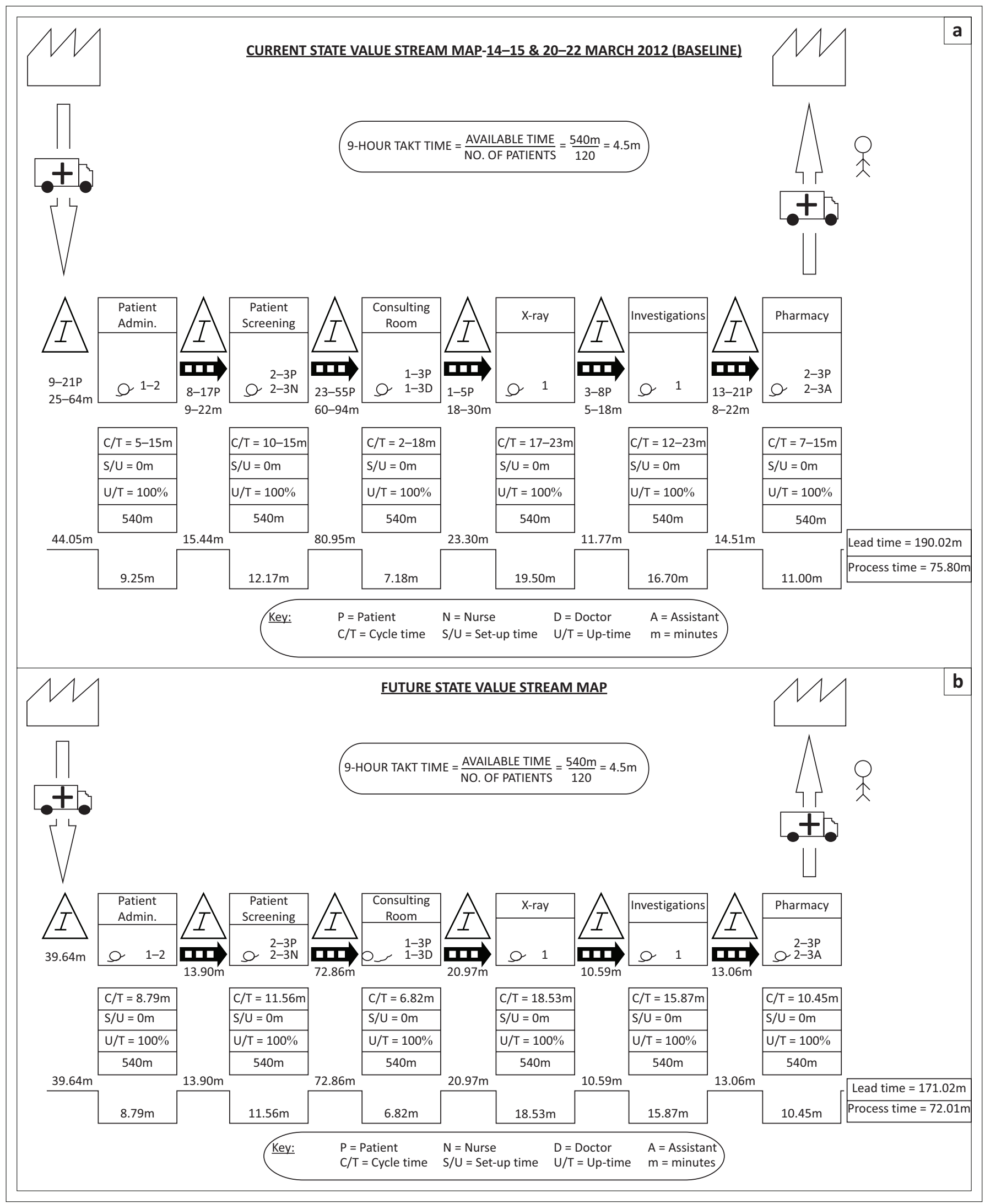

Source: Authors' own work

FIGURE 1: Current and future value stream mapping for outpatient department. 


\section{Takt time}

The takt-based waiting times indicate the total time spent waiting, based on demand for service. It is calculated by the formula: (takt time) $\times$ (number of patients waiting). The taktbased waiting time $(A)$ added to the cycle time $(B)$ for each service node provides us with the total time $(A+B)$ spent by the patient in the OPD, based on demand. Thus the valueadding cycle time $(B)$ as a percentage of the total time $(A+B)$ reflects the efficiency of the OPD.

The duration of all six service nodes that were open and operational during an ordinary weekday was 540 min (9 h) with $100 \%$ uptime (fully functional). The average patient throughput was 120 patients. Therefore, the 9-h takt time for the OPD (the cycle time necessary in the process to meet the demand of the patients) was calculated to be $4.5 \mathrm{~min}$. In other words, in an ideal 'production factory' setting, the OPD staff would spend 4.5 minutes 'processing' each 'inventory unit' (patient) in order to finish a 9-h day's work of 120 units (patients).

\section{Wastes and bottlenecks}

The problems and wastes that were identified were multifactorial. Patients with chronic medical conditions (such as hypertension and diabetes) presented on random days because there was no booking system, resulting in unpredictable demand. There was no patient-triage system in the OPD. The wastes and bottlenecks included: unnecessary and disorderly movement of staff (and patients), duplication of stationery and work, shortage of equipment, and improper processes and controls. Nurses were also not appropriately triaging patients and conducting appropriate vital signs observations, resulting in back-and-forth movement of patients in OPD, because doctors would not have the information they required during consultations.

\section{Measures implemented from kaizen team meetings}

A pre-consultation screening tool and a modified patienttriage system, consisting of a list of standing orders for various medical conditions, were implemented for nurses in the Patient Screening node. Patient queues and flows were reorganised such that the movement was more orderly and minimal. A one-way entrance and exit was created in the emergency room to facilitate flow of patients and staff.

A call bell was purchased and installed at the Patient Administration service node so that patients could alert staff that they need to be attended to immediately upon presentation. Lunch and tea breaks were staggered amongst

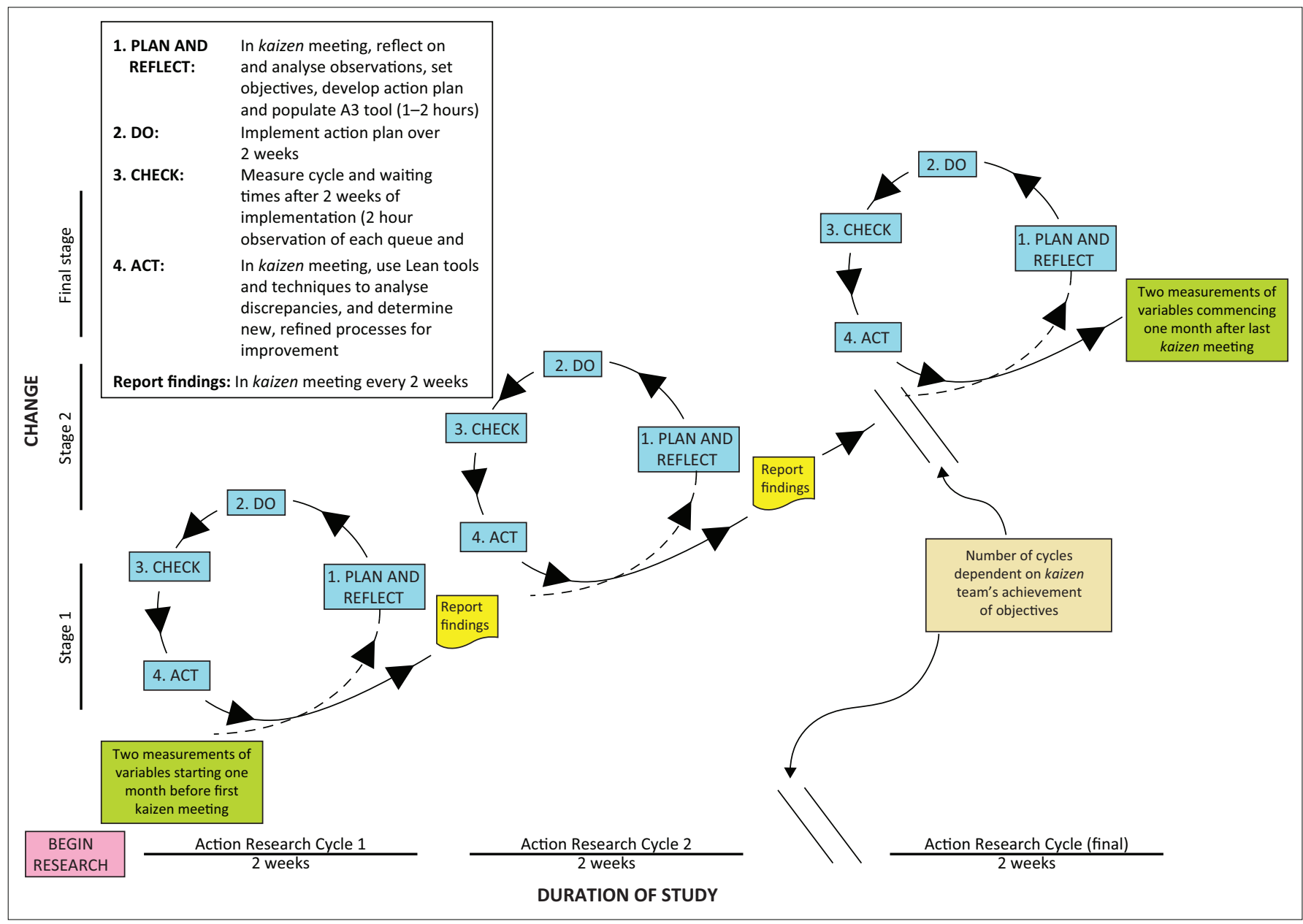

Source: Authors' own work

FIGURE 2: Iterative Plan-Do-Check-Act (PDCA) cycles for continuous quality improvement (19) during the application of Lean in a rural hospital. 
doctors and nurses so as to maintain the $100 \%$ uptime. A 'follow-up' slip was implemented. Once these were issued to patients who required follow-up, slips would be presented to the nurse in the Patient Screening node on their follow-up visit. This would then expedite service delivery: it would make the nurse aware of the specific reason for the patient's return, for example, for blood results. A dedicated file containing stationery used only by doctors was created for each Consulting room so as to reduce time searching for such stationery (Figure 2).

\section{Study population and sampling}

All outpatients observed in a queue preceding each service node during a midweek 2-hour standard observation period (same time, same place, and same days) were included in the sample (pre- and post-Lean implementation). Six service nodes were identified as fundamental in the delivery of outpatient services: Patient administration; Patient screening; Consulting room; X-ray department; Investigations; and Pharmacy.

The number of cycle time measurements $(n)$ for each service node was calculated using a formula ${ }^{19}$ consisting of $z=1.96$ (number of standard deviations from the mean reflecting level of statistical significance); $s=$ sample standard deviation of cycle time from the pilot study; $e=2 \mathrm{~min}$ (absolute amount of acceptable error); and level of confidence $=95 \%$, after measuring five cycle times in a pilot study (Table 1)

Because the number of waiting time measurements $(n)$ before each service node during the 2 -h observation periods depended on the nature of patient illness and the type of work carried out at the node, $n$ was variable during each action research cycle (Table 2).

TABLE 1: Sample size requirements for cycle time measurement at each service node.

\begin{tabular}{lcccc}
\hline Service node & $\begin{array}{c}\text { Maximum } \\
\text { time }\end{array}$ & $\begin{array}{c}\text { Minimum } \\
\text { time }\end{array}$ & Standard deviation & $\boldsymbol{n}$ \\
\hline Patient administration & 13 & 5 & 3.54 & 12 \\
Patient screening & 12 & 8 & 1.67 & 3 \\
Consulting room & 20 & 5 & 5.94 & 33 \\
X-ray & 22 & 18 & 1.48 & 2 \\
Investigations & 13 & 8 & 2.17 & 5 \\
Pharmacy & 20 & 12 & 3.08 & 9 \\
\hline
\end{tabular}

Source: Authors' own work. Calculated from the pilot study.

TABLE 2: Sample sizes for waiting times.

\begin{tabular}{lcccccc}
\hline Service node & \multicolumn{5}{c}{ Sample size for waiting times $(\boldsymbol{n})$ during each action research cycle } \\
\cline { 2 - 7 } & $\begin{array}{c}\text { First } \\
\text { baseline }\end{array}$ & $\begin{array}{c}\text { Second } \\
\text { baseline }\end{array}$ & Cycle 1 & Cycle 2 & $\begin{array}{c}\text { First } \\
\text { post-Lean }\end{array}$ & $\begin{array}{c}\text { Second } \\
\text { post-Lean }\end{array}$ \\
\hline $\begin{array}{l}\text { Patient } \\
\text { administration }\end{array}$ & 13 & 15 & 10 & 12 & 13 & 13 \\
$\begin{array}{l}\text { Patient } \\
\text { screening }\end{array}$ & 14 & 12 & 14 & 13 & 12 & 14 \\
$\begin{array}{l}\text { Consulting } \\
\text { room }\end{array}$ & 41 & 44 & 45 & 44 & 39 & 45 \\
$\begin{array}{l}\text { X-ray } \\
\text { Investigations }\end{array}$ & 8 & 5 & 3 & 3 & 4 & 3 \\
Pharmacy & 18 & 14 & 22 & 19 & 18 & 16 \\
\hline
\end{tabular}

Source: Authors' own work

\section{Data sources and data collection}

Cycle and waiting times were measured by direct observation on two occasions before, approximately two-weekly during, and on two occasions after Lean implementation. A data collection tool was completed by the professional nurses at each of the six key service nodes in the OPD. The watches of the professional nurses were synchronised at the commencement of the study (Figure 3).

\section{Data analysis}

The mean cycle and waiting time was calculated for each service point across all measurements. Because pre- and postintervention groups did not contain paired data (different participants at each pre- and post-intervention time point), they were considered as independent. Therefore, independent samples' $t$-tests were carried out to compare pre- and postintervention cycle and waiting times where the assumptions were met. Where the assumptions underlying the $t$-test were not met, the Wilcoxon rank-sum test was used to compare the baseline and post-intervention measurements. The test for trend was done by fitting a linear regression and evaluating the slope of the time variable. Statistical analyses were carried out using the $\mathrm{SPSS}^{\circledR}$ software package.

\section{Ethical considerations}

The study obtained ethics approval from the University of KwaZulu-Natal Biomedical Research Ethics Committee (BE097/11). Permission to conduct the study was obtained from the Hospital Manager, the Department of Health's uThungulu District Manager, and the KwaZulu-Natal Department of Health Provincial Health Research and Knowledge Management unit.

\section{Results}

\section{Pre-intervention (baseline) results}

The initial process flow analysis, cycle, and waiting times were conducted 14-15 and 20-22 March 2012. Each patient spent, on average, $189.8 \mathrm{~min}$ (range 2-23 $\mathrm{min}$ ) waiting in queues and $75.8 \mathrm{~min}$ (range 5-94 $\mathrm{min}$ ) in the service nodes being 'processed'. The lengths of the queues varied between the service points with the maximum queue length being at the consultation room (Table 3).

\section{Targets}

After two baseline measurements of cycle and waiting times at the specified intervals and the baseline survey, targets were set during the kaizen meetings and to develop a futurestate VSM. The team set a target of 5\% reduction in service time and a $10 \%$ reduction in waiting time (Table 4 ).

\section{Intermediate and post-Lean results}

At the end of each action research cycle, the cycle and waiting times were measured to determine trends and to evaluate implemented decisions for feedback during kaizen meetings. 


\section{CYCLE TIME MEASUREMENT FORM}

Sheet \#

The impact of Lean thinking on Operational Efficiency at a

District Hospital Outpatient Department in KwaZulu-Natal

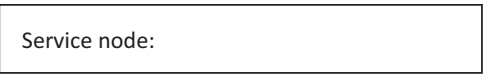

Observer:

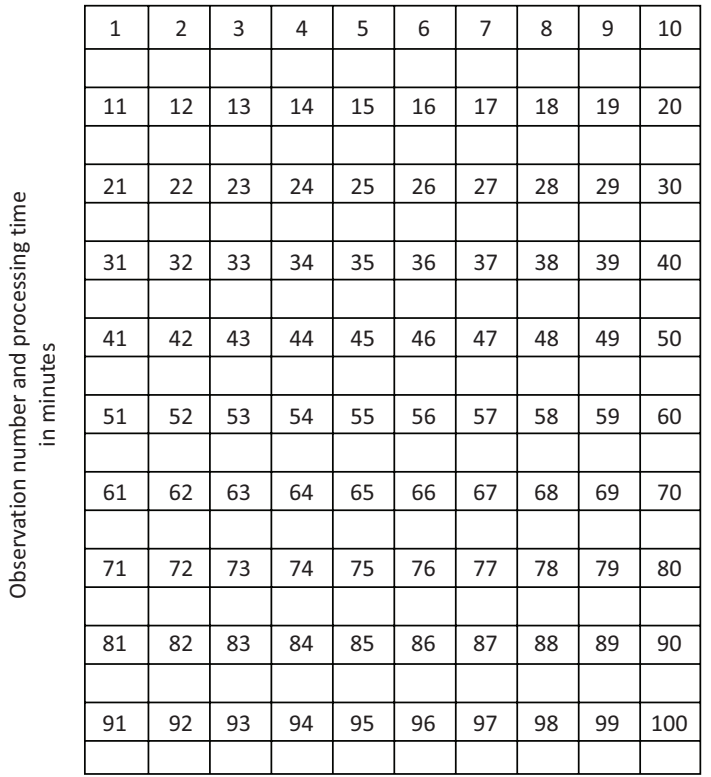

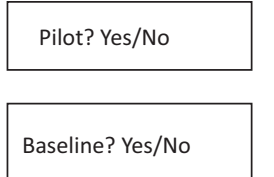

Time:

Research

Cycle\#:

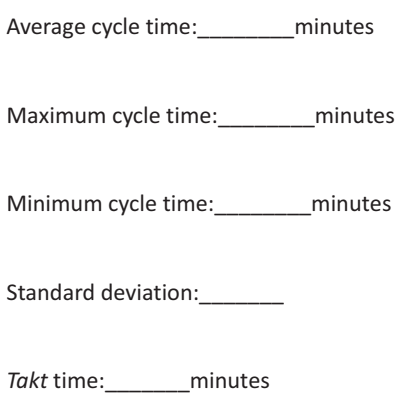

Service node cycle time: minutes

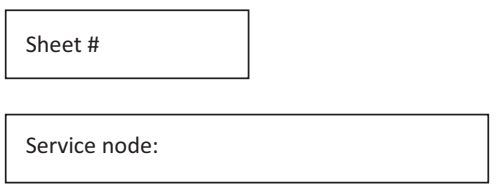

impact of Lean thinking on Operational Efficiency at a District Hospital Outpatient Department in KwaZulu-Natal

\section{Observer:}

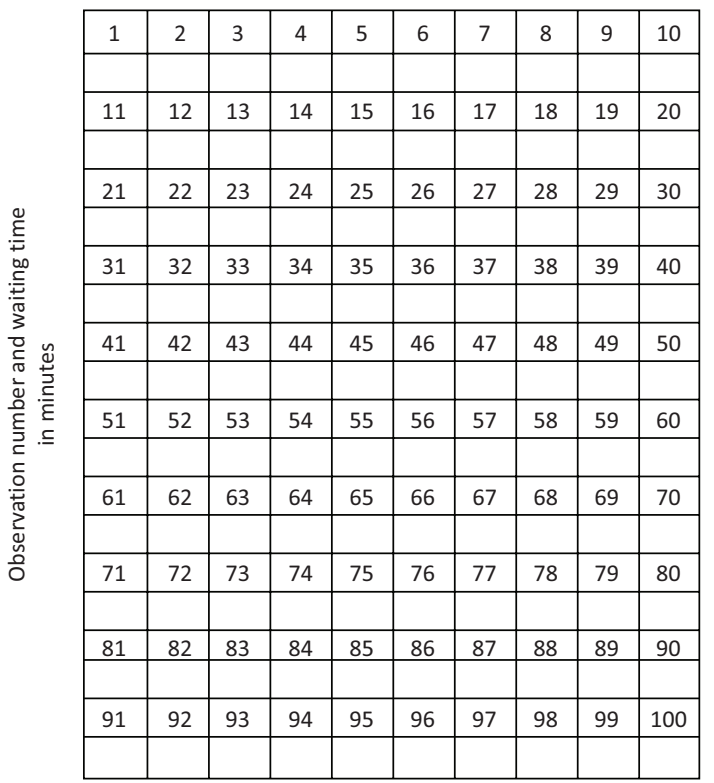

Maximum wait time:

Minimum wait time: Standard deviation:

Max. number in queue:

Min. number in queue:

Takt time:

Takt-based waiting time:
Baseline? Yes/No

\section{Research}

Cycle\#:
Date:

Start time of observ.:

End time of

observ.: minutes minutes minutes minutes 
Because only two further action research cycles were sufficient to reach the targets that were set at the outset, two sets of observations (16-17 May and 4-5 July 2012) and a final post-intervention measurement was carried out on 8-10 August 2012, respectively.

\section{Cycle times}

All six service nodes showed a reduction in cycle times between the baseline assessment and post-Lean implementation measurement. In comparison with baseline and target cycle times (Table 5), post-intervention observations showed that the set targets were met (and exceeded) in the following service nodes: Patient Administration ( 8 min; $p=0.16$ ); Patient Screening (10.33 min; $p=0.28$ ); and Investigations (12.2 min; $p=0.04)$. The only significant cycle time reduction was achieved in the Investigations node $(27 \% ; p<0.05)$.

\section{Waiting times}

Post-intervention waiting times also showed reductions for all six service nodes (Table 6), but the targets were met (and exceeded) for the following three service nodes; Patient Administration (37.77 min; $p=0.07$ ), Patient Screening (9.15 $\mathrm{min} ; p=0.25)$, and Investigations (10 $\mathrm{min} ; p=0.03$ ). There was a significant waiting time reduction $(p<0.05)$

TABLE 3: Baseline cycle and waiting times with minimum and maximum queue lengths and cycle and waiting times.

\begin{tabular}{|c|c|c|c|c|c|c|c|c|}
\hline Service node & $\begin{array}{l}\text { Baseline cycle time } \\
\text { (min) }\end{array}$ & $\begin{array}{l}\text { Baseline waiting time } \\
\text { (min) }\end{array}$ & $\begin{array}{l}\text { Max. queue } \\
\text { length }\end{array}$ & $\begin{array}{l}\text { Min. queue } \\
\text { length }\end{array}$ & $\begin{array}{l}\text { Max. cycle time } \\
\text { (min) }\end{array}$ & $\begin{array}{l}\text { Min. cycle time } \\
\text { (min) }\end{array}$ & $\begin{array}{l}\text { Max. waiting time } \\
\text { (min) }\end{array}$ & $\begin{array}{l}\text { Min. waiting time } \\
\text { (min) }\end{array}$ \\
\hline Patient administration & 9.25 & 44.14 & 21 & 9 & 15 & 5 & 64 & 25 \\
\hline Patient screening & 12.17 & 15.27 & 17 & 8 & 15 & 10 & 22 & 9 \\
\hline Consulting room & 7.18 & 80.95 & 55 & 23 & 18 & 2 & 94 & 60 \\
\hline X-ray & 19.50 & 23.33 & 5 & 1 & 23 & 17 & 30 & 18 \\
\hline Investigations & 16.70 & 11.93 & 8 & 3 & 23 & 12 & 18 & 5 \\
\hline Pharmacy & 11.00 & 14.16 & 21 & 13 & 15 & 7 & 22 & 8 \\
\hline Total & 75.80 & 189.78 & - & - & - & - & - & - \\
\hline
\end{tabular}

Source: Authors' own work

TABLE 4: Target cycle and waiting times.

\begin{tabular}{lccc}
\hline Service node & Baseline cycle time $(\mathbf{m i n})$ & Target $(\mathbf{m i n})$ & Baseline waiting time $(\mathbf{m i n})$ \\
\hline Patient administration & 9.25 & 8.79 & 44.05 \\
Patient screening & 12.17 & 11.56 & 15.44 \\
Consulting room & 7.18 & 6.82 & 30.95 \\
X-ray & 19.50 & 18.53 & 13.90 \\
Investigations & 16.70 & 15.87 & 72.86 \\
Pharmacy & 11.00 & 10.45 & 23.30 \\
\hline Total & $\mathbf{7 5 . 8 0}$ & $\mathbf{7 2 . 0 1}$ & 11.77 \\
\hline
\end{tabular}

Source: Authors' own work

TABLE 5: Progressive cycle time measurements.

\begin{tabular}{|c|c|c|c|c|c|c|c|}
\hline Service node & Baseline (min) & Cycle 1 (min) & Cycle 2 (min) & Post-Lean (min) & Target (min) & $\begin{array}{l}p \text {-value for baseline versus post-Lean } \\
\qquad(\alpha=0.05)\end{array}$ & $\begin{array}{l}p \text {-value for trend } \\
\quad(\alpha=0.05)\end{array}$ \\
\hline Patient administration & 9.25 & 8.17 & 8.08 & 8.00 & 8.79 & $0.16 \dagger$ & 0.14 \\
\hline Patient screening & 12.17 & 11.67 & 10.33 & 10.33 & 11.56 & $0.28+$ & 0.08 \\
\hline Consulting room & 7.18 & 6.03 & 6.85 & 7.03 & 6.82 & $0.82 \dagger$ & 0.98 \\
\hline X-ray & 19.50 & 26.50 & 20.00 & 19.00 & 18.53 & $1.00 \ddagger$ & 0.60 \\
\hline Investigations & 16.70 & 12.60 & 12.40 & 12.20 & 15.87 & $0.04 \ddagger$ & 0.01 \\
\hline Pharmacy & 11.00 & 9.78 & 11.22 & 10.78 & 10.45 & $0.79 \ddagger$ & 0.98 \\
\hline Total & 75.80 & 74.75 & 68.88 & 67.34 & 72.01 & - & - \\
\hline
\end{tabular}

Source: Authors' own work

$\dagger, t$-test was used where assumptions were met; otherwise the Wilcoxon test was used.

$\$$, Wilcoxon test comparing baseline and post-intervention cycle times.

TABLE 6: Progressive waiting time measurements.

\begin{tabular}{|c|c|c|c|c|c|c|c|}
\hline Service node & Baseline (min) & Cycle 1 (min) & Cycle 2 (min) & Post-Lean (min) & Target (min) & $\begin{array}{l}p \text {-value for baseline versus post-Lean } \\
\qquad(\alpha=0.05)\end{array}$ & $\begin{array}{l}p \text {-value for trend } \\
(\alpha=0.05)\end{array}$ \\
\hline Patient administration & 44.14 & 42.20 & 37.42 & 37.77 & 39.64 & $0.07 \dagger$ & 0.04 \\
\hline Patient screening & 15.27 & 14.00 & 9.85 & 9.15 & 13.90 & $0.25 \ddagger$ & $<0.0001$ \\
\hline Consulting room & 80.95 & 78.38 & 76.86 & 74.43 & 72.86 & $<0.01 \dagger$ & $<0.0001$ \\
\hline X-ray & 23.33 & 23.33 & 22.33 & 22.57 & 20.97 & $1.00 \ddagger$ & 0.71 \\
\hline Investigations & 11.93 & 10.80 & 10.00 & 10.00 & 10.59 & $0.03 \ddagger$ & 0.16 \\
\hline Pharmacy & 14.16 & 13.41 & 11.16 & 14.03 & 13.06 & $0.78 \div$ & 0.69 \\
\hline Total & 190.02 & 182.12 & 167.62 & 167.95 & 171.02 & - & - \\
\hline
\end{tabular}

Source: Authors' own work

$t, t$-test was used where assumptions were met; otherwise the Wilcoxon test was used.

$\$$ Wilcoxon test comparing baseline and post-intervention cycle times. 
for the Investigations node (from 11.93 to $10 \mathrm{~min} ; p=0.03$ ) and $(p<0.001)$ for the Consulting Room node (from 80.95 to $74.43 \mathrm{~min} ; p<0.0001$ ) although the target reduction was not achieved. Significant trends over time were noted in changes in waiting times for the Patient Administration $(p<0.05)$, Patient Screening $(p<0.001)$, and Consulting Room $(p<0.001)$ service nodes.

\section{Changes in takt-based waiting times and efficiency}

Pre-intervention efficiency in the OPD using takt-based calculations ranged from $16.00 \%$ (with maximum demand) to $16.69 \%$ (with minimum demand). In other words, between 16.00 and $16.69 \%$ of a patient's time in the OPD is spent receiving a service. The rest of the time is non-value-adding as it is spent waiting for a service.

The efficiency measured by the total observed cycle time as a percentage of the total time spent in the OPD, based on demand, changed over time since Lean implementation (Table 7). The average efficiency increased from 16.35\% (baseline) to $20.13 \%$ (post-Lean). During periods of maximum demand, the efficiency increased from $16.00 \%$ (baseline) to $17.20 \%$ (post-Lean), and during periods of minimum demand, the efficiency increased from $16.69 \%$ (baseline) to $23.05 \%$ (post-Lean).

\section{Discussion}

An improvement of total cycle time was noted throughout the Lean application process from 75.8 to $67.34 \mathrm{~min}$. These findings are supported by studies of Lean implementation in 15 EDs in the United States, Australia and Canada which showed patient care usually improved after implementation of Lean, with many EDs reporting decreases in length of stay, waiting times, and proportion of patients leaving the ED without being seen. ${ }^{20}$

The targeted total cycle time was exceeded, but was not met in three service nodes: Consulting Room, X-ray Department, and Pharmacy. The implementation of Lean in these three service nodes did reduce the cycle times from baseline, but the targets could not be met over a short period. Extrapolating the trend indicates that the targets for these three nodes would be met over a longer period of Lean implementation. The most likely explanation for this is the inflexible nature of the tasks carried out and the critical shortage of skilled labour in these nodes, including fluctuating staff levels because of service providers being on leave. Additional factors included: equipment problems (for example, X-ray machine breakdown); patient profiles; and disease acuity levels.
The only significant improvement in cycle times was noted in the Investigations section $(p<0.05)$. The primary reason was the implementation of the pre-consultation screening tool, which the nurses used. This tool empowered nurses to make decisions within their scope of practice and without waiting to be given instructions by doctors.

The modified triage system and the changes in layout and flow of patients in waiting areas, were the most important contributors to waiting time reductions for the Patient Screening and Consulting Room nodes. The changes in waiting-room layout allowed for patients to sit closer to the proceeding service node and move in a one-way direction (flow). ${ }^{12}$ Furthermore, the layout allowed for segregation of high-risk groups (such as coughing adult patients) from susceptible groups (children and the elderly) for infection control purposes, thus contributing to the quality aspect of Lean.

The successful implementation of the Lean health practices at this rural district hospital can be attributed to the following critical success factors as previously noted in the literature. ${ }^{20}$

- There was recognition that a problem existed and that improvements were needed.

- A human-centred approach was adopted whereby the employees were involved and part of the solution generation from the onset.

- The medical manager or implementing agent had knowledge of and skills in Lean and educated the staff on the various principles.

- The hospital management endorsed the quality improvement initiative.

- The medical manager acted as the project champion and facilitator.

- Numerous kaizen meetings were convened and the solutions were generated based on local needs and adapted accordingly.

- Regular kaizen meetings allowed for review of performance and continuous improvements.

\section{Study limitations and strengths}

Although this study was conducted in an OPD setting in only one hospital, this research documents a number of lessons and experiences that other managers in developing countries may find useful. This research used a pragmatic approach to the Lean intervention, rather than an experiment in an artificial setting. The research therefore retained the complexities of the real world, and this considerably improved the chances of reproducing similar results in other settings.

TABLE 7: Trend in efficiency in the outpatient department (OPD) over the study period.

\begin{tabular}{|c|c|c|c|c|c|c|c|c|}
\hline \multirow{2}{*}{$\frac{\text { Research cycle }}{\text { Efficiency based on }}$} & \multicolumn{2}{|c|}{ Baseline } & \multicolumn{2}{|c|}{ Cycle 1} & \multicolumn{2}{|c|}{ Cycle 2} & \multicolumn{2}{|c|}{ Post-Lean } \\
\hline & Min. demand & Max. demand & Min. demand & Max. demand & Min. demand & Max. demand & Min. demand & Max. demand \\
\hline Efficiency & $16.69 \%$ & $16.00 \%$ & $21.66 \%$ & $16.98 \%$ & $22.97 \%$ & $17.16 \%$ & $23.05 \%$ & $17.20 \%$ \\
\hline Average efficiency & \multicolumn{2}{|c|}{$16.35 \%$} & \multicolumn{2}{|c|}{$19.32 \%$} & \multicolumn{2}{|c|}{$20.07 \%$} & \multicolumn{2}{|c|}{$20.13 \%$} \\
\hline
\end{tabular}

Source: Authors' own work 
One of the limitations of the study was the lack of enthusiasm from some of the staff in implementing decisions made by the kaizen team. Owing to the short study period, the change in culture of the organisation with Lean implementation was impeded, even though this was not one of the objectives of the study.

A further limitation to the study was the postponement of some of the scheduled kaizen meetings owing to other staff engagements and priorities. This caused interference with the intervals for measurement of cycle and waiting times in each action research cycle.

The inherent variability in dealing with patients and the nature of the work in the OPD makes the prerequisite of creating stable and predictable flow, an important limitation to the study ${ }^{21}$

Furthermore, there was no comparison group to identify a causal relationship between the intervention and outcomes. However, the action research team felt confident in ascribing the changes observed to the intervention.

\section{Conclusion and recommendations}

The application of Lean principles, tools and techniques provides hospital managers with an evidence-based management approach to resolving problems and improving quality indicators in key focus areas, such as patient waiting times. With the potential benefits of Lean in other departments and facets of health care in a hospital setting, the kaizen team should extend their quality improvement efforts to applying Lean elsewhere in the hospital, such as to the wards, theatre, and pharmacy.

\section{Acknowledgements}

The authors wish to express their heartfelt gratitude to the managers and supervisors at the Catherine Booth Hospital, the uThungulu District Manager at the time of the study, M.M. Zungu, and the Department of Health for permitting the study to take place.

\section{Competing interests}

The authors declare that they have no financial or personal relationships that may have inappropriately influenced them in writing this article.

\section{Authors' contributions}

L.N. was the project leader, conducted the research and measurements, and produced the report in partial requirements for the degree of Master of Public Health. O.H.M. made conceptual contributions and drafted the manuscript.

\section{References}

1. National Department of Health. White paper for the transformation of the health system in South Africa. Pretoria: National Department of Health; 1997.

2. English $M$, Lanata $C$, Ngugi I, Smith P. The District Hospital. In Jamison DT, Breman JG, Measham AR, et al., editors. Disease control priorities in developing countries. 2nd ed. Washington, DC: World Bank: 2006. p1211-1229.

3. Norman R, Bradshaw D, Schneider M, Pieterse D, Groenewald P. Revised burden of disease estimates for the comparative risk factor assessment, South Africa 2000. Methodological Note. Cape Town: Medical Research Council, Burden of Disease Unit; 2006.

4. Harrison D. An overview of health and health care in South Africa $1994-2010$ Priorities, Progress and Prospects for New Gains. Discussion Document. Muldersdrift: Henry J. Kaiser Family Foundation; 2009.

5. Department of Health. National Service delivery agreement 2010-2014. Pretoria: Department of Health; 2010.

6. National Department of Health. Fast track to quality: The six most critical areas for patient-centered care. Pretoria: National Department of Health, Office of Standards Compliance; 2011.

7. National Department of Health. National core standards for health establishments in South Africa. Pretoria: Office of Standards Compliance, National Department of Health; 2011.

8. Dansky K, Miles M. Patient satisfaction with ambulatory healthcare services: Waiting time and filling time. Hosp Health Serv Adm. 1997;42(2):165-177.

9. Huang $X$. Patient attitude towards waiting in an outpatient clinic and its applications. Health Serv Manage Res. 1994;7(1):2-8.

10. Mazzocato P, Savage C, Brommels M, Aronsson $H$, Thor J. Lean thinking in healthcare: A realist review of the literature. Qual Saf Health Care. 2010;19(5): 376-382.

11. Khan N, Jain S. Quality initiatives in the emergency department. Curr Opin Paediatr. 2010;22(3):262-267

12. Holden R. Lean thinking in emergency departments: A critical review. Ann Emerg Med. 2011;57(3):265-278.

13. Chan $H$, Lo $S$, Lee $L$, et al. Lean techniques for the improvement of patients' flow in emergency department. World J Emerg Med. 2014;5(1):24-28.

14. Sastry M, Long KS, Salie $\mathrm{H}$, et al. Collaborative action research to reduce patient wait times: Results in two high-demand public clinics in Western Cape, South Africa. Cape Town: University of Cape Town, Graduate School of Business; 2015.

15. Price J. Lean Management in the South African public sector: A case study. In: Padarath A, English R, editors. South African health review 2013/14. Durban Health System Trust; 2014: p.191-201.

16. Jones D, Mitchell A. Lean thinking for the NHS. A report commissioned by the NHS Confederation. London: NHS Confederation; 2006.

17. Zidel T. A Lean toolbox - Using Lean principles and techniques in healthcare. J Healthc Qual. 2006;28:W1-7.

18. Sobek D, Jimmerson C. A3 Reports: Tool for organizational transformation. Bozeman, MT: Department of Mechanical and Industrial Engineering, Montana State University; 2006

19. Deming W. Out of the crisis. Cambridge, MA: Center for Advanced Engineering Study, Massachusetts Institute of Technology; 1986.

20. Lwanga S, Lemeshow S. Sample size determination in health studies: A practical manual. Geneva: World Health Organization; 1991.

21. Stepaniak P. Modeling and management of variation in the operating rooms helps to improve patient outcome. Pol J Surg. 2012;84(2):63-69. 